\title{
Carnets
}

Revue électronique d'études françaises de l'APEF

Première Série - 1 Numéro Spécial | 2009

Cultures littéraires : nouvelles performances \& développement

\section{Comunicação transbordante e contagiante / conhecimento acossado e arrefecido}

\section{Eunice Cabral}

\author{
(2) OpenEdition \\ Journals \\ Edição electrónica \\ URL: http://journals.openedition.org/carnets/3509 \\ DOI: $10.4000 /$ carnets.3509 \\ ISSN: 1646-7698 \\ Editora \\ APEF
}

Edição impressa

Data de publição: 1 Junho 2009

Paginação: 65-74

Refêrencia eletrónica

Eunice Cabral, « Comunicação transbordante e contagiante / conhecimento acossado e arrefecido », Carnets [Online], Première Série - 1 Numéro Spécial | 2009, posto online no dia 16 junho 2018, consultado o 24 abril 2019. URL : http://journals.openedition.org/carnets/3509 ; DOI : 10.4000/ carnets.3509

Carnets est mis à disposition selon les termes de la licence Creative Commons - Atribution - Pas d'utilisation commerciale 4.0 International. 


\title{
COMUNICAÇÃO TRANSBORDANTE \\ E CONTAGIANTE / CONHECIMENTO \\ ACOSSADO E ARREFECIDO
}

\author{
EUNICE CABRAL \\ Universidade de Évora \\ eunice.cabral@netcabo.pt
}

\begin{abstract}
Resumo
A importância da literatura enquanto conhecimento não tem tido lugar num tempo caracterizado pela circulação da informação e da comunicação das culturas literárias. Os procedimentos da comunicação de massas relativos às culturas literárias tendem a reduzir a literatura a um conjunto de objectos transaccionáveis que compete com outros objectos culturais, todos eles em busca de visibilidade efectiva, de comercialização eficiente e de legitimação. A comunicação, ao apoderar-se de todo o espaço público pela imposição de um tipo de discurso amalgamado, caótico e sem regras provoca uma competição deslegitimada na cena mediática. Os produtos resultantes são atingidos pela ausência de valor e pelo progressivo desgaste da significação num contexto de circulação veloz e imediata e de exposição rasa mas insistente e constante.
\end{abstract}

\begin{abstract}
The present condition of the Portuguese cultural and social context indicates a growing tension between normalization and singularity, in spite of being slightly perceived in certain spheres. The normalization of Portuguese society (José Gil, 2004) materializes itself in apathy and torpidity. If it's true that the cultural industry is more active than never, it's also evident that the literary cultures have been dissolved and forgotten. In this mass communication context which leads to a torpid perception of the cultural reality, singularity is a desire, or even an utopia that, in spite of indicating some possible directions, it's felt by its absence. The literary cultures can thus activate ways of producing subjectivity.
\end{abstract}

Palavras-chave: Comunicação, Sociedade do conhecimento, Culturas literárias

Keywords: Communication, Knowledge society, Literary cultures 


\section{O desvanecimento do conhecimento a partir das culturas literárias}

Todos os períodos têm os seus paradoxos próprios. Só quem os vive na pele, sendo seu contemporâneo, os considera como tal visto que o tempo se encarregará de os resolver, dando-Ihes respostas mais ou menos satisfatórias ou, então, dissolvendo-os por desgaste e apagando-os por falta de actualidade.

Esta consideração vem a propósito de um dos muitos paradoxos da cultura contemporânea. No que à literatura diz respeito, uma multiplicidade e uma variedade de culturas literárias, que se traduzem em autorias no sentido forte do termo, em obras publicadas, em hermenêuticas literárias e em publicações diversificadas entre si coexistem e circulam de modo eficiente e alargado. Esta actividade cultural, ligada à literatura, que faz com que as obras literárias obtenham visibilidade, que faz com que os livros obtenham divulgação, não tem sido capaz de produzir conhecimento reconhecido e legitimado sobre a contemporaneidade. Por outras palavras: a informação e a comunicação das culturas literárias, circulando num ambiente marcado pela heterogeneidade e pela aparente democratização, não se concretizam nem se traduzem em propostas de conhecimento. A abundância e a diversidade de propostas da área da literatura não parecem ter sido capazes de contribuir para a chamada "sociedade do conhecimento». Desta situação de "arrefecimento" e de "irrelevância" resulta que a literatura, a hermenêutica a ela ligada e o seu ensino não se encontram na primeira linha do mapa actual do conhecimento.

Antes de prosseguir, há que distinguir inequivocamente dois domínios afectos às culturas literárias: o domínio da publicidade e da divulgação das obras literárias em que o texto "publicitário" anuncia as características em termos de valor de troca de uma obra (a informação) e o domínio da avaliação, da análise e do estudo da obra em que o estudioso, o analista ou o crítico, sejam ele quais forem, têm por função exercer uma atitude reflexiva em relação ao objecto em causa pelo seu saber acumulado (o conhecimento).

Sendo o desenvolvimento tecnológico o principal factor do ambiente cultural contemporâneo, as culturas literárias não se furtam à sua influência, tendo vindo a ser moldadas pela circulação de índole "comunicativa" e de inspiração tecnológica em que o denominador económico, comercial e industrial tem predominado. Esta realidade não deveria inibir o domínio do conhecimento; antes co-adjuvá-lo através de uma atitude de reflexão e de saber sobre a literatura. De modo correlato, a quantidade não deveria opor-se de modo simplista à qualidade. Bem pelo contrário: encontrando-se o meio cultural transbordante de propostas literárias, então a reflexão em torno da literatura deveria ser igualmente diversificada e contagiante, revelando-se necessária. De facto, "o topos da qualidade", característico da racionalidade estético-expressiva (Santos, 2002: 96) não 
deveria ser inibido pela quantidade ("o topos da quantidade"), mas, antes, orientá-la no sentido da criação e da sustentabilidade de uma "proliferação de comunidades interpretativas" (Santos, 2002: 90).

A realidade actual, no entanto, apresenta-se de modo rasamente dicotómico: por um lado, a comunicação de índole tecnológica das culturas literárias encontra-se em clara expansão e, por outro lado, o conhecimento reflexivo sobre a literatura está em franca retracção. Por exemplo: as "comunidades interpretativas", que bem poderiam beneficiar da inovação tecnológica, não têm proliferado e as que existem, como as comunidades universitárias, não se fazem ouvir e não têm peso nas decisões em momentos-chave da História mais recente. Parecem sobreviver esgotadas pela desatenção geral e acossadas por um «espírito da época» que não lhes é favorável.

Em relação à situação descrita, constatamos duas reacções distintas. Uma das reacções, constituindo uma apreciação positiva do panorama actual e não vendo nele aspectos negativos, não verá sequer um paradoxo mas, antes, a situação ideal para a democratização das culturas literárias no sentido de uma mais rápida e mais eficiente divulgação para públicos mais diversificados. Outra reacção, mais pessimista (na linha da que é aqui formulada), interpreta o "arrefecimento" do conhecimento como resultante do funcionamento hegemónico da comunicação, que acaba por dissolver a importância da literatura enquanto produção de conhecimento.

Definamos o que entendemos por comunicação. A comunicação resulta da combinação da sociedade de massas e de consumo interpenetrada e difundida pelo desenvolvimento tecnológico. Aliás, mais do que um tipo de funcionamento que interpenetra e faz circular, a comunicação de índole tecnológica é a própria cultura massificada, tal como a conhecemos actualmente. Por outras palavras: a comunicação, resultante das inovações tecnológicas a funcionar por simples automatismo e sem limites, molda a informação através de processos de simplificação e de trivialização dos conteúdos. Opera por contracção, por redução e por uniformização, desfigurando a mensagem por amálgama, por não estabelecer diferenciações e por esvaziar de significado as palavras e as frases. O mecanismo produz a insignificância da cultura que faz circular através de um funcionamento por acumulação indiferenciada. Assim sendo, as questões tratadas de modo "comunicativo" misturam-se e confundem-se, interpenetrando-se numa lógica de indiferenciação e eximindo-se a qualquer determinação de índole intelectual, cognitiva e reflexiva.

A comunicação não suprime a mensagem ocultando-a mas anula-a através de uma exposição exagerada e desenfreada de todas as suas variantes, funcionando sem critérios discerníveis para o receptor. Em suma, a comunicação dissolve os conteúdos, ao estabelecer uma relação de analogia, de continuidade e de semelhança entre todas as produções culturais (Perniola, 2005: 11-15). De facto, o propósito de tornar visíveis as obras 
literárias como produtos de consumo assenta numa cultura de prestação de serviços impessoal, normalizada e rapidamente acessível pela qual o público recebe o produto de forma imediata, consumindo-o mas sem estabelecer comparações nem distinções, num processo em que as questões não são problematizadas. A comunicação, entendida e praticada nestes moldes, promove a acumulação indistinta, impede a hierarquia de valores e inibe o estabelecimento de prioridades; "abafa" o consumidor com produtos cujas características são distorcidas pela difusão de modo totalmente mercantilizado da cultura. Funciona por meio do caos e da força, apropriando-se de tudo pela anulação das diferenças mediante a igualização de todas as coisas (Perniola, 2005: 18-24). Num universo cultural com estas características, só a comunicação imediata, directa e instantânea existe; aliás, o acto comunicativo desaparece rapidamente como apareceu numa sucessão de actos sem que deles fique qualquer tipo de registo. Por conseguinte, a ausência de significação prende-se com a circulação cada vez mais rápida no sentido de o produto em destaque se encontrar acessível de modo intenso, sendo substituído logo por outro sem que o "consumidor" possa adquirir conhecimento a partir dele (saber que existe e poder adquiri-lo é uma coisa mas ficar com ele, reflectir e apropriar-se dele para a sua vida é outra bem diferente).

Ao veicular produtos culturais em relação aos quais não são apresentadas provas legítimas do que é dito e afirmado (Perniola, 2005: 25), a comunicação procede pela incoerência do pensamento (discordância), pela incoerência da acção (dissociação) e pela incoerência do sentimento (desagregação) (Perniola, 2005: 43-45). A falta de método, a inconsequência e a confusão, factores da comunicação de massas actual (Perniola, 2005: 11), aniquila o conhecimento pelo processo de homologação e de nivelamento da variedade das experiências, canalizando-as através de um único registo impessoal e insignificante. Funcionando deste modo rápido e eficiente mas linear, as múltiplas dimensões da realidade são negadas e reduzidas a uma só. Sendo totalitária sem o afirmar, a comunicação torna o seu funcionamento único e sem réplica: ocupa de modo hegemónico o espaço público através da desvalorização do confronto de ideias, não dando a oportunidade nem a possibilidade para debates entre perspectivas distintas e, nessa medida, nega a existência da vida intelectual. Em suma: a comunicação representa a "catástrofe da significação» na medida em que nada do que é dito neste ambiente (o da comunicação) pode ser objecto de interpretação (Perniola, 2005: 33). Aliás, a comunicação pretende ser tudo o que a rodeia, aderindo a formas e a conteúdos que amalgama por osmose e que dissolve num movimento de aniquilação da significação, tornando-se no oposto do conhecimento. No que toca ao campo das culturas literárias, este torna-se "liso" e ecléctico pelo poder avassalador de divulgação apoiado na ambivalência e na indeterminação. Deste modo, as culturas literárias, 
sendo enquadradas e veiculadas pelo funcionamento da comunicação, arriscam-se a tornarse apenas entretenimento inconsequente.

\section{A atitude paradoxal de desencantamento/distanciamento e de proximidade física}

No que às literaturas diz respeito, a comunicação confunde-se com a divulgação das literaturas, actividade comercial desde há muito consagrada e, como tal, aceitável e até louvável. Por conseguinte, a visibilidade e a circulação mais intensas das literaturas parecem um benefício à primeira vista. Mas o que há de excepcional, nos tempos actuais, é que a comunicação dos produtos literários fez desaparecer a consciência auto-reflexiva ligada às culturas literárias, tornando a visibilidade e a circulação das obras profundamente ambígua, ao negar a possibilidade de estabelecer hierarquias e critérios para a diferenciação das obras literárias e ao suprimir ou ao marginalizar as "comunidades interpretativas".

Sendo a lógica da comunicação prevalecente no mundo cultural contemporâneo, a reflexividade, contendo aspectos de diferenciação e de integração, é relegada como inoperante e indesejada; é vista como lenta, sem rendimento, inútil. Por contraste, a comunicação é uma forma de eclectismo que indetermina tudo em que toca ao promover uma concepção de linguagem que se apresenta como estando impossibilitada de dizer o que quer que seja de significativo na medida em que se encontra inibida de verificar e de regular qualquer tipo de valor (Perniola, 2005: 15), neste caso, o literário. A comunicação acaba por veicular e reproduzir os abusos da impessoalidade e da desresponsabilização (Kerckhove, 1997: 234), ou seja, faz circular um tipo de discurso aparentemente neutro contra a tradição individualista, baseada num diálogo de consciências que querem e podem intervir no mundo circundante.

Por conseguinte, as manifestações da reflexividade sobre a literatura são vistas pela sua rival, a comunicação, como fazendo parte da vida intelectual, que vive do conflito e da discordância, apoiada em argumentações lógicas e éticas. Ora, a comunicação anuncia pelo modo como funciona que a vida intelectual é um procedimento do passado porque se rege por processos alheios ao desenvolvimento tecnológico e à rapidez de circulação da cultura. Em vez da reflexão e da crítica como atitude perante e no mundo, a comunicação promove o desejo de protagonismo e de afirmação a todo o custo em que a aparência conta mais do que a substância no sentido em que impera a vontade de se tornar visível no mundo dos media (Perniola, 2005: 19-20). 
Tomemos como exemplo a crítica literária como uma parte das culturas literárias como conhecimento. A crítica literária, de facto, tem sido marginalizada (senão mesmo silenciada) pelo desenvolvimento tecnológico que se manifesta de dois modos complementares: a acumulação indistinta de produtos culturais (por exemplo, as obras literárias como texto integral são amalgamadas em igualdade de circunstâncias com resumos, adaptações televisivas, cinematográficas numa indiferenciação de teor pósmoderno) e a acumulação de dispositivos tecnológicos ligados à cultura (dvd, cd, internet, canais televisivos, etc.). Em suma, sendo a comunicação uma das manifestações do desenvolvimento tecnológico e sendo este recebido e reproduzido automaticamente e sem limites, todo o procedimento dotado de um funcionamento distinto, como é o caso do conhecimento de tipo reflexivo sobre a literatura, é desqualificado e tendencialmente suprimido. O fenómeno da comunicação de massas reduz a literatura (tal como a ciência, a política e a arte) a um conjunto de objectos, de produtos "mudos" que são dados a ver a sujeitos objectualizados. Os leitores são eles próprios objectos da circulação, «coisas entre coisas», sem que haja espaço real para a constituição da subjectividade e da singularização a partir das culturas literárias. Com efeito, do lado do receptor e para que este funcionamento resulte, é necessário um certo tipo de leitor: este é encarado como um mero consumidor de cultura através de uma apropriação imediata e não reflexiva de objectos de consumo. Assim sendo, o público desejado pelo fenómeno de comunicação de massas não tem memória nem inconsciente (Perniola, 2005: 92). Com um tal funcionamento, tudo se imobiliza, apesar do movimento. Em última análise, a comunicação pode ser entendida como um dos pontos de chegada do desenvolvimento científico moderno para o qual só existe o ser humano enquanto «sujeito epistémico» mas não como «sujeito empírico». Ou melhor: o funcionamento da comunicação, no que às culturas literárias diz respeito, representa a incapacidade em estabelecer relação com o outro na medida em que todo o outro está transformado em objecto (Santos, 2002: 77 - 79).

De facto, para a acumulação indistinta e indiferenciada das culturas literárias, em que estas circulam como objectos ou produtos desqualificados e residuais, têm contribuído dois factores cruciais: a "condenação" ao desenvolvimento ilimitado das tecnologias e o apelo deste tipo de desenvolvimento à fisicalidade humana. $O$ primeiro diz respeito à atitude de distanciamento e de desencantamento, característicos da ciência moderna. Esta atitude alimenta e reproduz, sem entraves à vista, o desenvolvimento tecnológico, marcado pelo utopismo automático, sem que nenhuma instância consiga formular limites, redimensionamentos ou orientações para a inovação contínua, sendo que a evolução desta situação parece suscitar consequências imprevisíveis. O outro factor decisivo é o teor "físico" despertado e activado pelos artefactos tecnológicos. Expliquemo-nos: a era da televisão abriu um precedente desconhecido até então que consiste na comunicação que 
não é mental mas física. É Derrick de Kerckhove que diz que «a televisão fala, em primeiro lugar, ao corpo e não à mente». Por esta razão, «a televisão é hipnoticamente envolvente» (Kerckhove, 1997: 38 - 39). Por conseguinte, segundo estudos sobre esta matéria, a televisão elimina o efeito de distanciamento entre o estímulo e a reacção, o que se traduz pelo facto de a televisão deixar pouco ou nenhum tempo para reflectir sobre o que o espectador está a ver (Kerckhove, 1997: 41).

Ao fim e ao cabo, habitamos um mundo envolvente que nos interpela fisicamente de modos inesperados e insistentes, impossíveis de evitar para o qual não temos explicações satisfatórias. Este parece ser um período de acumulação "selvagem" de imagens, de construções, de arquitecturas que são lidas e recebidas como artefactos e como objectos culturais. Por existirem no espaço que nos cerca sob a forma de uma abundância indiscriminada, não parece possível por agora ter redes consistentes de sentido e de significação para estes fenómenos. Nesse sentido, o nosso é um período cuja comunidade é vivida de modo passivo; existem procedimentos, actividades e muitas novidades mas não parece haver agentes nem intérpretes legitimados. A cadeia de acontecimentos, muito variada, como já se disse, tem uma recepção marcada pela passividade, pelo desprendimento e pelo alheamento.

\section{Dinâmica do conhecimento e comunidades interpretativas}

A dinâmica das culturas literárias, se verdadeiramente existisse, deveria apontar para situações em que se registariam modalidades de percepção e de recepção das obras literárias pela intervenção dos vários agentes que, de modo directo ou indirecto, dialogariam e interagiriam entre si. No caso das culturas literárias, são eles os escritores, os leitores, os críticos, os ensaístas, os professores, os editores, os directores de programas culturais, etc.. Seria num contexto de conflito de interpretações, de propostas distintas, mas que não se ignoram, que as culturas literárias deveriam funcionar e evoluir. Por exemplo, a crítica literária, como uma das manifestações das culturas literárias, funciona em moldes totalmente diferentes da comunicação, tal como foi aqui definida, porque a crítica separa, classifica, diferencia, atribuindo valor ou desvalorizando através da apresentação ou da exposição de uma argumentação. Se o cenário for devidamente democrático, não haverá uma só interpretação mas várias; nenhuma delas é absoluta nem imposta mas baseada numa argumentação exposta a refutação. Assim sendo, a defesa da interpretação como valor não significa a aceitação de um "monopólio de interpretação" (Santos, 2002: 90): Bem pelo contrário: representa uma das conquistas do "fim dos monopólios de interpretação" (Santos, 2002: 90) levada a cabo com êxito pela modernidade. Com efeito, tais monopólios, 
hoje em dia inexistentes ou muito enfraquecidos, estiveram tradicionalmente nas mãos da religião, da família, do partido político ou do Estado.

Acontece que a comunicação impõe subrepticiamente um outro tipo de restrição, que é "a renúncia à interpretação" (Santos, 2002: 90). Deste modo, a aparente permissividade, resultante da "renúncia à interpretação", acaba por accionar o que José Gil chama a regra invisível que rege a sociedade de forma a normalizá-la e a imobilizar o panorama da cultura (Gil, 2007). Perniola, por sua vez, caracteriza a contemporaneidade como regida pelo "pensamento único" (Perniola, 2005: 96). Boaventura de Sousa Santos refere a "visão única" (Santos, 2002: 224) que domina o tempo actual.

Estas comunidades interpretativas, se existissem e se interagissem, deveriam ter expressão pelo uso da memória e da imaginação, pelo uso da diferenciação argumentativa baseada no saber e no conhecimento. Por exemplo, as universidades poderiam ter um papel determinante no desenvolvimento do conhecimento das culturas literárias. Para que tal acontecesse, as universidades deveriam ocupar-se em assegurar níveis de reflexividade sobre a literatura nos seus ensinos, em editoras de prestígio a si ligadas ou revistas, o que não significaria que a "qualidade" académica tivesse que inevitavelmente inibir ou dificultar a divulgação ou viver num reduto de ciência, incomunicável com o resto do mundo e do conhecimento. Afinal, foram o fechamento e a subsequente ausência de circulação do conhecimento produzido nas universidades que deixaram o terreno completamente livre à comunicação, tal como a caracterizámos.

Voltamos ao paradoxo com o qual iniciámos esta comunicação: a acumulação, a circulação e a difusão em larga escala e sem precedentes das culturas literárias não se têm feito acompanhar do conhecimento dessas mesmas culturas. A pessoa pode estar informada mas não conhece, na medida em que informação não é igual a conhecimento. Entendemos que o conhecimento de uma área é a faculdade de reflectir por associações entre aspectos variados e de produzir "objectos" novos (textos, discursos) através da memória e da imaginação. As culturas literárias poderão activar formas de produção da subjectividade se se tornarem conhecimento e não forem meros prolongamentos da comunicação. Para sair da lógica da comunicação, há que centrar a atenção na importância da escolha e da distinção entre factores de uma cultura.

É um facto que vivemos num mundo sem fronteiras, sem lideranças reconhecidas e sem regulação. Tudo se vai aglomerando de modo nivelado sem que alguma instância tenha a capacidade de distinguir os elementos dessa "aglomeração", não já para impor uma "ordem", que lembraria os tempos excessivamente ideológicos e unidireccionados, coincidentes grosso modo com a primeira metade de Novecentos, mas para permitir a interacção e a evolução através da distinção reflexiva. 
As culturas literárias, assentes na consciência auto-reflexiva que se opõe à divulgação caótica e acrítica dos produtos literários, podem ajudar o leitor a escrever o seu próprio programa de acção e tomar decisões criativas e autónomas no sentido da evolução humana. 


\section{Bibliografia}

CsIKSZEntMIHAlYI, Mihaly (1993), The Evolving Self; ed. ut.: Novas Atitudes Mentais - Uma Psicologia para o Terceiro Milénio (1998), Círculo de Leitores.

CoELHO, Eduardo Prado (2004), O Fio da Modernidade, Lisboa: Editorial Notícias.

GIL, José (2007), Portugal, Hoje - O Medo de Existir, $11^{\text {a }}$ ed., Lisboa: Relógio D’ Água Editores.

KERCKHOVE, Derrick de (1995), The Skin of Culture (Investigating the New Electronic Reality), Toronto e Ontário, Canadá: Somerville House Books Limited; ed. ut.: A Pele da Cultura - Uma Investigação Sobre a Nova Realidade Electrónica (1997), Lisboa: Relógio D’ Água Editores.

Perniola, Mario (2004), Contro la comunicazione, Milão: Giulio Einaudi editore; ed. ut.: Contra a Comunicação (2005), Lisboa: Editorial Teorema.

SANTOS, Boaventura de Sousa (2002), A Crítica da Razão Indolente - Contra o Desperdício da Experiência, $2 \stackrel{a}{ }$ ed., Porto: Edições Afrontamento. 